\title{
Clinical evaluation of prophylactic abdominal aortic balloon occlusion in patients with placenta accreta: a systematic review and meta-analysis
}

\author{
Li Chen ${ }^{1,2,3}$, Xiaodan Wang ${ }^{1}$, Hengyu Wang ${ }^{1}$, Qin $\mathrm{Li}^{1}$, Nan Shan ${ }^{1,2,3^{*}}$ and Hongbo Qi ${ }^{1,2,3^{*}}$
}

\begin{abstract}
Background: Severe obstetric hemorrhage caused by placenta accreta results in significant maternal morbidity and mortality. As a new technology, abdominal aortic balloon occlusion (AABO) is becoming an important treatment for patients with placenta accreta. To evaluate the safety and efficacy of AABO, we conducted a systematic review and meta-analysis of previous studies.

Methods: We used a three-check subset including placenta accreta (placenta previa, percreta, increta, etc.), balloon, and aortic (aortas, aorta, etc.) to form a retrieval formula and searched in MEDLINE, EMBASE, the Cochrane Library, clinicaltrials.gov and Web of Science. All articles regarding placenta previa or placenta accreta and including the use of abdominal aortic balloon occlusion were included in our screening. Two researchers selected articles and extracted data independently. Finally, the Newcastle-Ottawa Quality Assessment Scale was used for quality assessments.

Results: We retrieved 776 articles and eventually included 11 clinical studies. Meta-analysis showed that AABO significantly reduced the blood loss volume (MD $-1480 \mathrm{ml}, 95 \% \mathrm{Cl}-1806$ to $-1154 \mathrm{ml}, P<0.001)$ and blood transfusion volume (MD $-1125 \mathrm{ml}, 95 \% \mathrm{Cl}-1264$ to $-987 \mathrm{ml}, P<0.001)$. Similarly, obvious reductions in the hysterectomy rate (OR $0.30,95 \% \mathrm{Cl} 0.19$ to $0.48, P<0.001$ ), hospitalization duration ( $\mathrm{MD}-1.35$ days, $95 \% \mathrm{Cl}-2.40$ to -0.31 days, $P=0.01$ ), and operative time (MD $-29.23 \mathrm{~min}, 95 \% \mathrm{Cl}-46.04$ to $-12.42 \mathrm{~min}, P<0.001)$ were observed in the $A A B O$ group.
\end{abstract}

Conclusion: The prophylactic use of AABO in patients with placenta accreta is safe and effective.

Keywords: Placenta accreta, Abdominal aortic balloon occlusion, Cesarean section

\section{Introduction}

The mechanism of morbidly adherent placenta (MAP) is still unknown. MAP is a pathophysiological change in which the placental villus invades the myometrium of the uterus due to dysplasia of the decidua basalis or a traumatic endocardial defect [1]. A case-control study showed that the incidence of MAP was $1.7 / 10000$ among all delivering women, and that the proportion was as high as 577/10000 among pregnant women with

\footnotetext{
*Correspondence: 31426193@qq.com; qihongbocy@gmail.com

${ }^{1}$ The Department of Obstetrics, The First Affiliated Hospital of Chongqing

Medical University, Chongqing 400016, China

Full list of author information is available at the end of the article
}

placenta previa and a history of previous cesarean section [2]. As the global rate of cesarean section increases [3], especially in China, with a rate of close to $50 \%$ and even higher in some cities, the incidence of MAP is also increasing. Placenta accreta causes massive hemorrhage, disseminated intravascular coagulation (DIC), and liver and kidney damage and can even require hysterectomy. Placenta percreta not only easily causes injury to the bladder and ureters but also increases patients' susceptibility to developing life-threatening hemorrhage. The average blood loss volume in patients with placenta increta or percreta has been reported to be $3000 \mathrm{ml}$, and

(c) The Author(s). 2019 Open Access This article is distributed under the terms of the Creative Commons Attribution 4.0 International License (http://creativecommons.org/licenses/by/4.0/), which permits unrestricted use, distribution, and reproduction in any medium, provided you give appropriate credit to the original author(s) and the source, provide a link to the Creative Commons license, and indicate if changes were made. The Creative Commons Public Domain Dedication waiver (http://creativecommons.org/publicdomain/zero/1.0/) applies to the data made available in this article, unless otherwise stated. 
this volume exceeds $5000 \mathrm{ml}$ in $20 \%$ of patients and even $10,000 \mathrm{ml}$ in $10 \%$ of patients $[4,5]$.

Previously, hysterectomy was the main approach implemented when uncontrollable hemorrhage occurred during cesarean surgery in patients with placenta accreta. However, hysterectomy permanently affects fertility, and some women may want another child. In recent decades, some intravascular interventional therapies have been used in obstetrics to reduce intraoperative bleeding and decrease the rate of hysterectomy, including uterine artery embolization, common iliac artery balloon occlusion, and bilateral internal iliac artery balloon occlusion [6-8]. Due to the abundant collateral circulation of the uterus, the efficacy of the above methods is limited, and these methods may even cause complications, such as hematoma, thrombosis, arterial injury, and bladder injury.

The prophylactic use of abdominal aortic balloon occlusion $(\mathrm{AABO})$ in patients with placenta accreta is a new strategy that has been applied in obstetrics in recent years $[9,10]$. Interventional doctors insert a balloon catheter into the lower segment of the abdominal aorta beneath the opening of the renal arteries through the right femoral artery. After the fetus is delivered and the cord is clamped, the balloon is immediately inflated to block the uterine blood supply temporarily to minimize hemorrhage when the surgeon manually removes the placenta and sutures the uterine incision. Although some related articles have been published, little is known about the efficacy of this method as these studies report contradictions that may be related to clinical heterogeneity. Given this lack of knowledge, we collected related articles and performed a systematic review and meta-analysis to evaluate the safety and efficacy of AABO.

\section{Materials and methods}

\section{Search strategy}

We retrieved literature from MEDLINE, EMBASE, the Cochrane Library, clinicaltrials.gov and Web of Science and used $\mathrm{MeSH}$ and text words to generate a three-check subset including placenta accreta (placenta previa, percreta, increta, etc.), balloon, and aortic (aortas, aorta, etc.). The retrieval formula for this research was generated using "AND" to connect the three subsets. The search included no specific language restrictions and was completed by two individuals.

\section{Study selection and data extraction}

The population investigated included pregnant women with placenta accreta who delivered by cesarean section. Those in the experimental group underwent $\mathrm{AABO}$ before surgery, while those in the control group underwent direct cesarean section without balloon occlusion. Individual patients with contraindications to $\mathrm{AABO}$ or other intervention methods were excluded in each article. The outcomes obtained were intraoperative

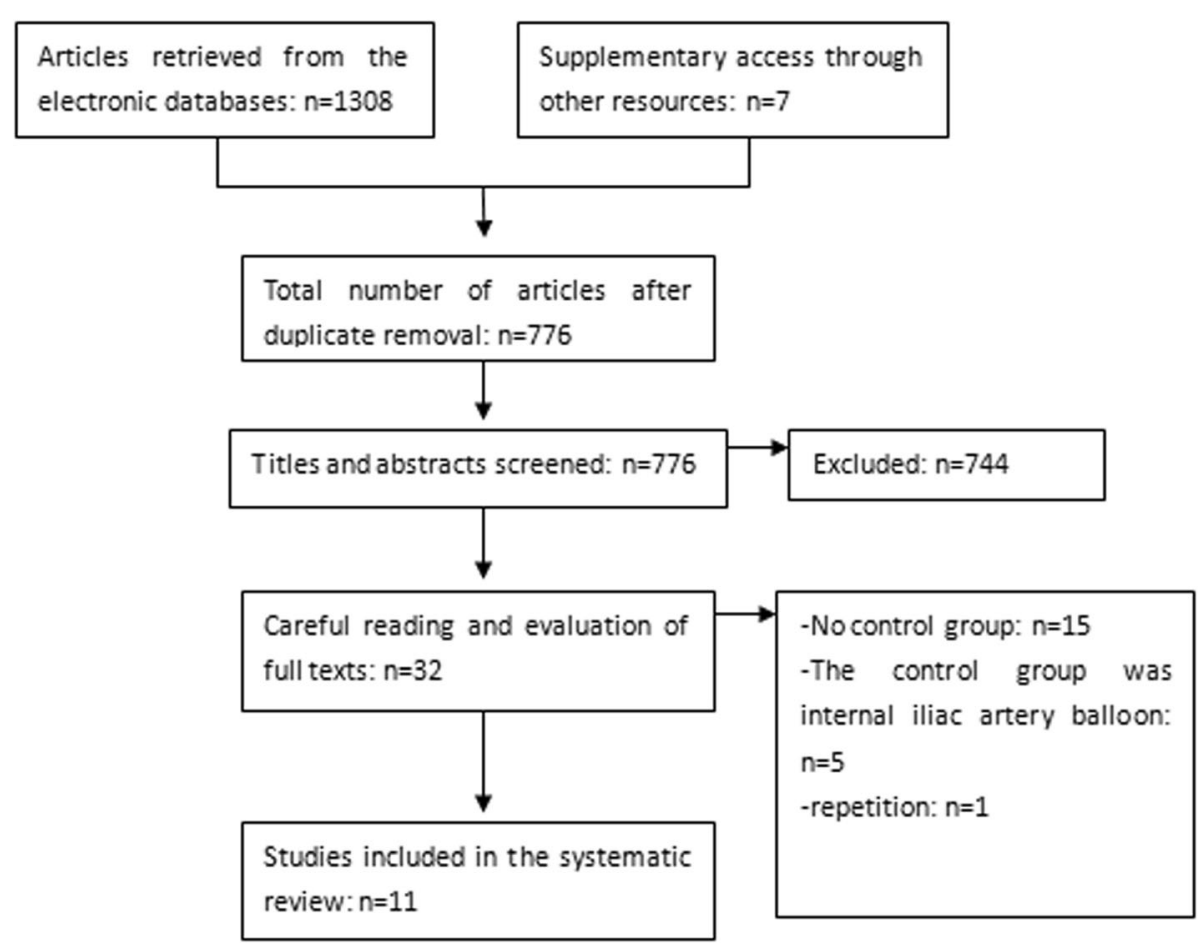

Fig. 1 Study selection process for the meta-analysis and the inclusion and exclusion criteria 


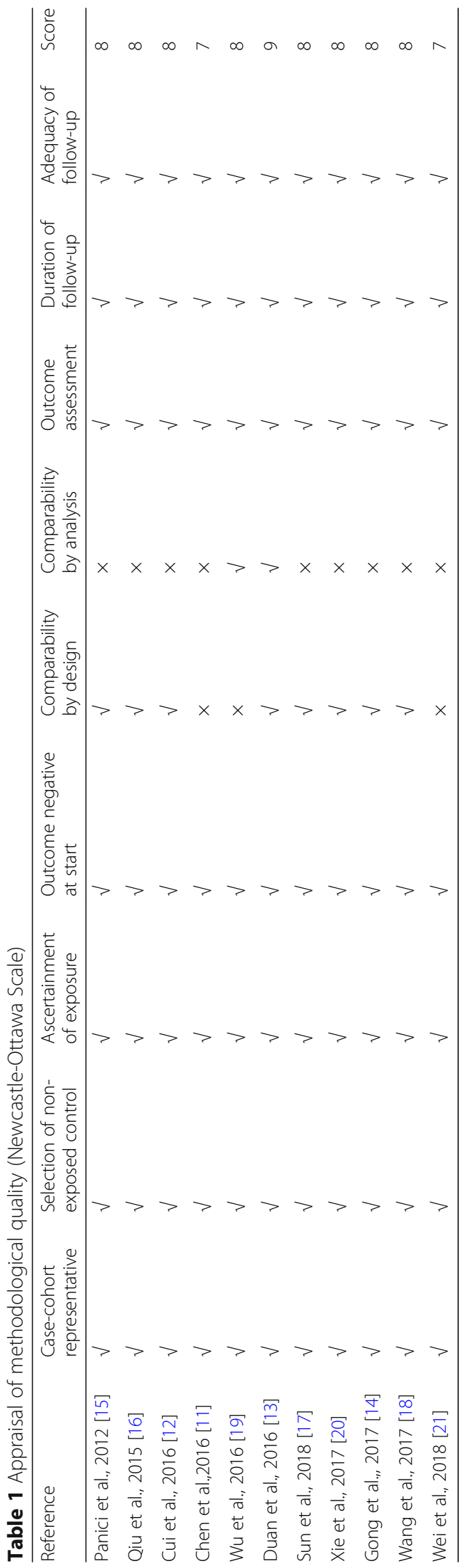




\begin{tabular}{|c|c|c|c|c|c|c|c|c|c|c|}
\hline \multirow[b]{2}{*}{ Study or Subgroup } & \multicolumn{3}{|c|}{ AABO group(100ml) } & \multicolumn{3}{|c|}{ NO-AABO group(100ml) } & \multirow[b]{2}{*}{ Weight } & \multirow{2}{*}{$\begin{array}{l}\text { Mean Difference } \\
\text { IV. Random. } 95 \% \mathrm{Cl}\end{array}$} & \multirow{2}{*}{\multicolumn{2}{|c|}{$\begin{array}{l}\text { Mean Difference } \\
\text { IV. Random, } 95 \% \mathrm{Cl}\end{array}$}} \\
\hline & Mean & SD & Total & Mean & SD & Total & & & & \\
\hline Chen 2016 & 11.55 & 3.937 & 20 & 20.174 & 8.747 & 23 & $13.3 \%$ & $-8.62[-12.59,-4.65]$ & & \\
\hline Duan 2016 & 5.86 & 3.55 & 32 & 24.85 & 5.6 & 30 & $15.2 \%$ & $-18.99[-21.34,-16.64]$ & - & \\
\hline Gong 2017 & 9.3211 & 0.8254 & 53 & 20.1053 & 2.8669 & 19 & $16.1 \%$ & $-10.78[-12.09,-9.48]$ & - & \\
\hline Qiu 2015 & 12.9 & 3.9 & 10 & 36.6 & 8.46 & 10 & $10.9 \%$ & $-23.70[-29.47,-17.93]$ & & \\
\hline Wei 2018 & 8.5 & 1 & 20 & 25 & 2.3 & 20 & $16.3 \%$ & $-16.50[-17.60,-15.40]$ & $\pi$ & \\
\hline Wu 2016 & 9.21 & 1.99 & 230 & 27.9 & 3.35 & 38 & $16.3 \%$ & $-18.69[-19.79,-17.59]$ & 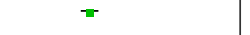 & \\
\hline Xie 2017 & 9.61 & 7.84 & 30 & 15.6 & 13.53 & 41 & $11.9 \%$ & $-5.99[-10.99,-0.99]$ & & \\
\hline Total $(95 \% \mathrm{Cl})$ & & & 395 & & & 181 & $100.0 \%$ & $-14.80[-18.06,-11.54]$ & & \\
\hline $\begin{array}{l}\text { Heterogeneity: } \mathrm{Tau}^{2}= \\
\text { Test for overall effect: }\end{array}$ & $\begin{array}{l}16.74 ; \mathrm{Ch} \\
\mathrm{Z}=8.89(\end{array}$ & $\begin{array}{l}i^{2}=126.3 \\
P<0.000\end{array}$ & $\begin{array}{l}\text { 5. } d f=6 \\
\text { 1) }\end{array}$ & $(P<0.000$ & 1); $\left.\right|^{2}=95$ & & & & $\begin{array}{ccc}-20 & -10 & 0 \\
\text { Favours [experimental] }\end{array}$ & $\begin{array}{ccc}0 & 10 & 20 \\
\text { Favours [control] }\end{array}$ \\
\hline
\end{tabular}

hemorrhage, blood transfusion volume, hysterectomy, postoperative hospitalization duration, operative time, neonatal status and complications.

The study was divided into three steps. In the first step, two individuals independently reviewed the titles and abstracts of identified articles and then obtained the full texts of the articles that seemed relevant to this study. In the second step, these individuals carefully read the original texts and selected articles for inclusion or exclusion. In the last step, the latest or most complete versions of duplicated articles were selected, and any disagreements were arbitrated by a third party. The quality assessment was completed by two researchers using the Newcastle-Ottawa Quality Assessment Scale.

\section{Statistical analysis}

Fixed-effects models were used to analyze the hysterectomy outcome in each study because the corresponding data showed good homogeneity. The remaining data were analyzed using random-effects models because of their obvious heterogeneity. The heterogeneity of exposure factors across these studies was assessed by forest plots and quantified by the $\mathrm{I}^{2}$ statistic. Funnel plots were adopted to evaluate publication bias. Finally, Review Manager 5.3 was used for the statistical analysis.

\section{Results}

A total of 776 articles were identified in the electronic databases and other resources using the retrieval formula,
744 of which were excluded based on the titles and abstracts. The full texts of the remaining 32 studies were read, and 11 articles were finally included. All the included articles described observational studies with the target population (patients with placenta accreta) and whether the patients selected AABO after doctors explained each treatment option in detail (exposure factor) [11-21]. Twenty-one studies were excluded as summarized in Fig. 1.

All 11 included studies were published between 2012 and 2018 and contained a total of 731 patients. Among these patients, 463 chose to undergo AABO, while the other 268 patients did not (NO-AABO). The corresponding Newcastle-Ottawa Quality Assessment results are presented in Table 1.

\section{Meta-analysis}

Overall, 7 articles compared intraoperative hemorrhage between the AABO and NO-AABO groups. The prophylactic use of $\mathrm{AABO}$ before surgery significantly reduced the blood loss volume compared with no AABO (MD $-1480 \mathrm{ml}, 95 \% \mathrm{CI}-1806$ to $-1154 \mathrm{ml}, P<0.001$ ) (Fig. 2). The blood transfusion volume was reported in 6 studies; overall, patients who underwent $\mathrm{AABO}$ required fewer PRBC unit transfusions than those who did not undergo AABO (MD $-1125 \mathrm{ml}$, 95\% CI -1264 to $-987 \mathrm{ml}, P<$ 0.001) (Fig. 3). The difference in the hysterectomy rate between patients who underwent $\mathrm{AABO}$ and those who did not was compared in all 11 studies. Similarly, obvious

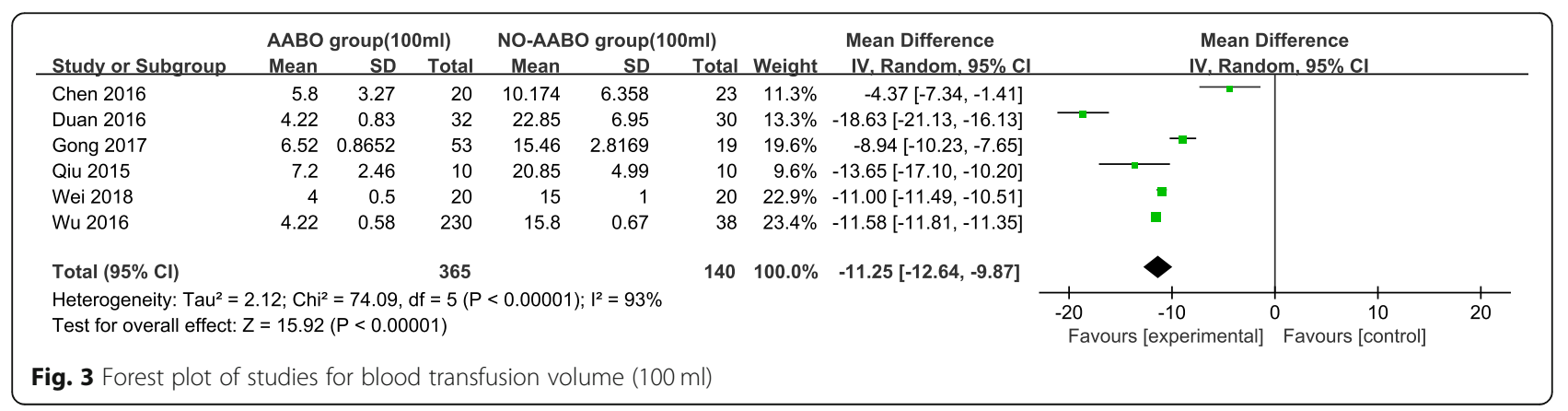




\begin{tabular}{|c|c|c|c|c|c|c|c|c|c|}
\hline \multirow[b]{2}{*}{ Study or Subgroup } & \multicolumn{2}{|c|}{ AABO group(n) } & \multicolumn{2}{|c|}{ NO-AABO group(n) } & \multirow[b]{2}{*}{ Weight } & \multirow{2}{*}{$\begin{array}{l}\text { Odds Ratio } \\
\text { M-H, Fixed, } 95 \% \mathrm{Cl}\end{array}$} & \multirow{2}{*}{\multicolumn{3}{|c|}{$\begin{array}{c}\text { Odds Ratio } \\
\text { M-H, Fixed, } 95 \% \mathrm{Cl}\end{array}$}} \\
\hline & Events & Total & Events & Total & & & & & \\
\hline Chen 2016 & 4 & 20 & 12 & 23 & $14.2 \%$ & $0.23[0.06,0.90]$ & & & \\
\hline Cui 2016 & 0 & 24 & 2 & 24 & $3.9 \%$ & $0.18[0.01,4.04]$ & & & \\
\hline Duan 2016 & 1 & 32 & 7 & 30 & $11.1 \%$ & $0.11[0.01,0.92]$ & & & \\
\hline Gong 2017 & 5 & 53 & 6 & 19 & $12.7 \%$ & $0.23[0.06,0.86]$ & & & \\
\hline Panici 2012 & 2 & 15 & 9 & 18 & $11.3 \%$ & $0.15[0.03,0.89]$ & & & \\
\hline Qiu 2015 & 3 & 10 & 3 & 10 & $3.3 \%$ & $1.00[0.15,6.77]$ & & & \\
\hline Sun 2018 & 4 & 19 & 6 & 12 & $9.2 \%$ & $0.27[0.05,1.29]$ & & & \\
\hline Wang 2017 & 7 & 10 & 21 & 33 & $4.6 \%$ & $1.33[0.29,6.14]$ & & & \\
\hline Wei 2018 & 1 & 20 & 6 & 20 & $9.0 \%$ & $0.12[0.01,1.14]$ & & & \\
\hline Wu 2016 & 0 & 230 & 3 & 38 & $9.5 \%$ & $0.02[0.00,0.43]$ & 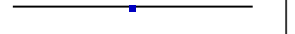 & & \\
\hline Xie 2017 & 5 & 30 & 10 & 41 & $11.2 \%$ & $0.62[0.19,2.05]$ & & & \\
\hline Total $(95 \% \mathrm{Cl})$ & & 463 & & 268 & $100.0 \%$ & $0.30[0.19,0.48]$ & & & \\
\hline Total events & 32 & & 85 & & & & & & \\
\hline \multicolumn{7}{|c|}{$\begin{array}{l}\text { Heterogeneity: } \mathrm{Chi}^{2}=12.05, \mathrm{df}=10(P=0.28) ; I^{2}=17 \% \\
\text { Test for overall effect: } Z=4.92(P<0.00001)\end{array}$} & $\begin{array}{ccc}0.001 & 0.1 & 1 \\
\text { Favours [experimental] }\end{array}$ & $\begin{array}{l}1 \\
\text { Favours [control] }\end{array}$ & 1000 \\
\hline
\end{tabular}

differences were found between the two groups (OR $0.30,95 \%$ CI 0.19 to $0.48, P<0.001$ ) (Fig. 4). Seven articles listed the operative time, with a clearly reduced time in the $\mathrm{AABO}$ group compared with that in the NO-AABO group (MD - 29.23 min, 95\% CI -46.04 to $12.42 \mathrm{~min}, P<0.001$ ) (Fig. 5). Meta-analysis of the 6 studies that reported the number of postoperative hospitalization days as an outcome showed a significant reduction in the postoperative hospitalization duration with $\mathrm{AABO}$ (MD -1.35 days, $95 \% \mathrm{CI}-2.40$ to -0.31 days, $P=0.01$ ) (Fig. 6).

Four studies reported no obvious differences in Apgar scores between the AABO and control groups, with a mean score of greater than 8 . Regarding intraoperative or postoperative maternal complications, among 4 articles, the numbers of disseminated intravascular coagulation (DIC) events were 0 and 8 in the AABO and control groups, respectively. In addition, a total of 3 cases of hematoma at the puncture site and 5 cases of venous thrombus were reported in the AABO group, with a balloon-related morbidity rate of $1.7 \%(n=8 / 463)$. These patients were all cured during hospitalization. However, in addition to the 8 cases of DIC, 12 cases of hemorrhagic shock due to uncontrollable hemorrhage resulting from manual removal of the placenta were reported in the control groups.

\section{Evaluation of publication bias}

Funnel plots for articles evaluating $A A B O$ versus $\mathrm{NO}-\mathrm{AABO}$ in terms of the hysterectomy rate showed asymmetry on visual inspection, with gaps suggesting that few studies with negative results have been published (Fig. 7).

\section{Discussion}

This study is the first systematic review and metaanalysis to evaluate the safety and efficacy of AABO during manual removal of the placenta during cesarean section in patients with placenta accreta. The conclusion of this study is that compared with no AABO, the prophylactic use of AABO has a beneficial effect by decreasing hemorrhaging and blood transfusion requirements during or after surgery. Patients treated with $\mathrm{AABO}$ had lower hysterectomy and DIC rates. Additionally, the operative time and postoperative hospitalization duration were shorter in the $\mathrm{AABO}$ group than those in the NO-AABO group.

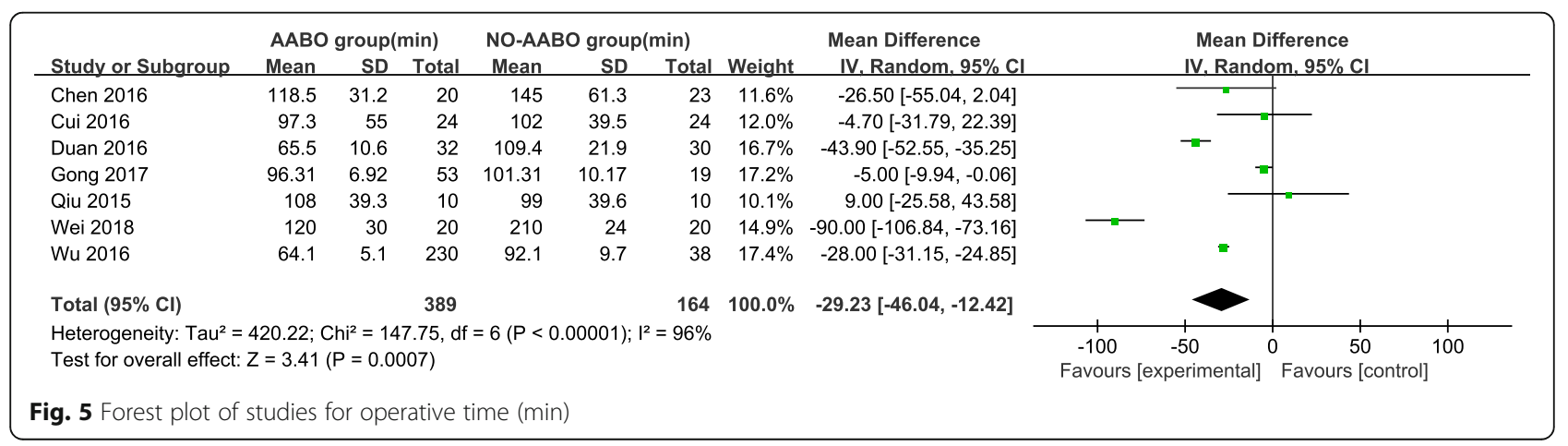




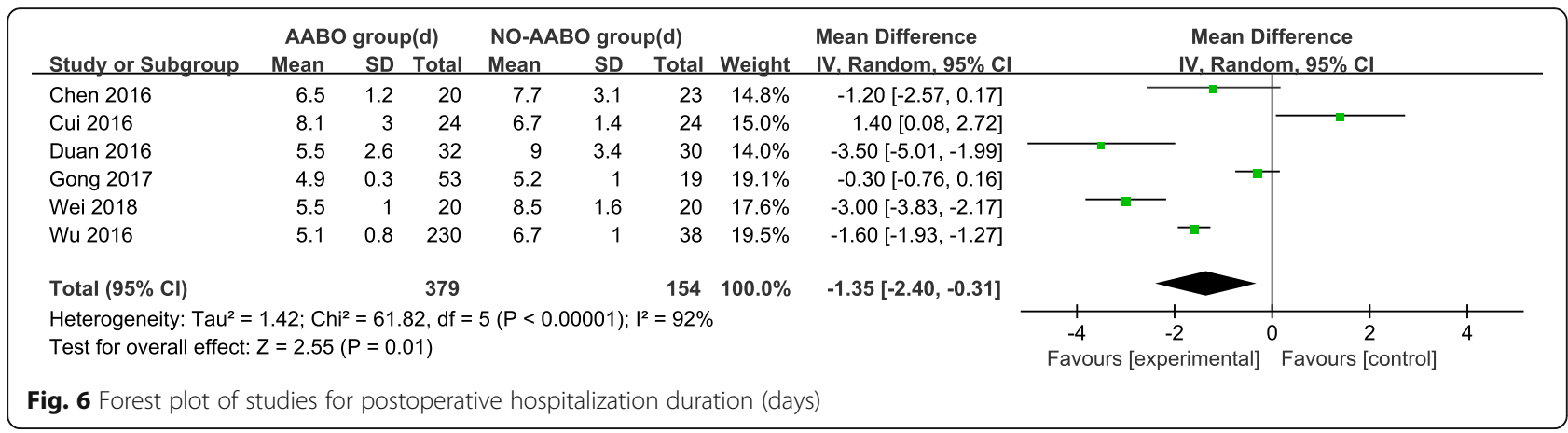

The main complications of AABO were thrombus and hematoma at the puncture site, with an incidence rate of $1.7 \%(n=8 / 463)$. These patients all recovered spontaneously or with thrombolytic therapy. Compared with no $\mathrm{AABO}, \mathrm{AABO}$ prevented some severe complications caused by uncontrollable hemorrhage after manual removal of the implanted placenta, while 8 cases of DIC and 12 cases of hemorrhagic shock were reported in the NO-AABO group.

The weaknesses of our study are mainly related to the heterogeneity of the results. We read the original articles again in an attempt to identify the source of the heterogeneity from among the features of the population, inconsistencies in the exposure factors and differences in the methodologies; however, no significant differences were found among these studies. Therefore, we speculate that the heterogeneity may originate at the levels of the surgeon, patient condition assessments, and blood loss volume estimations. In addition, although most articles mentioned that the patients included in their studies were complicated with placenta increta or percreta, they did not describe the specific area and depth of placental implantation in detail, which may be one of the sources of heterogeneity.

Some scholars have expressed concerns that X-rays cause fetal damage. The International Commission on Radiological Protection (ICRP) suggests that the fetal teratogenic risk does not increase when the radiation dose is less than $100 \mathrm{mGy}$ [22]. In this study, all articles reported fetal radiation exposure doses of less than $10 \mathrm{mGy}$. Three other articles compared $\mathrm{AABO}$ and bilateral internal iliac artery balloon occlusion in terms of the radiation dose and concluded that $\mathrm{AABO}$ resulted in a lower fetal radiation dose [23-25], indicating that $A A B O$ is safer for fetuses than other endovascular interventional treatments in patients with placenta accreta. In our study, no puerperal or neonatal complications caused by radiation were reported during the follow-up period.

With the development of endovascular interventional treatments, some scholars have attempted to apply a balloon catheter to the distal abdominal aorta, bilateral common iliac artery or internal iliac artery in patients with placenta accreta to temporarily block uterine blood flow and provide adequate time for surgeons. However,

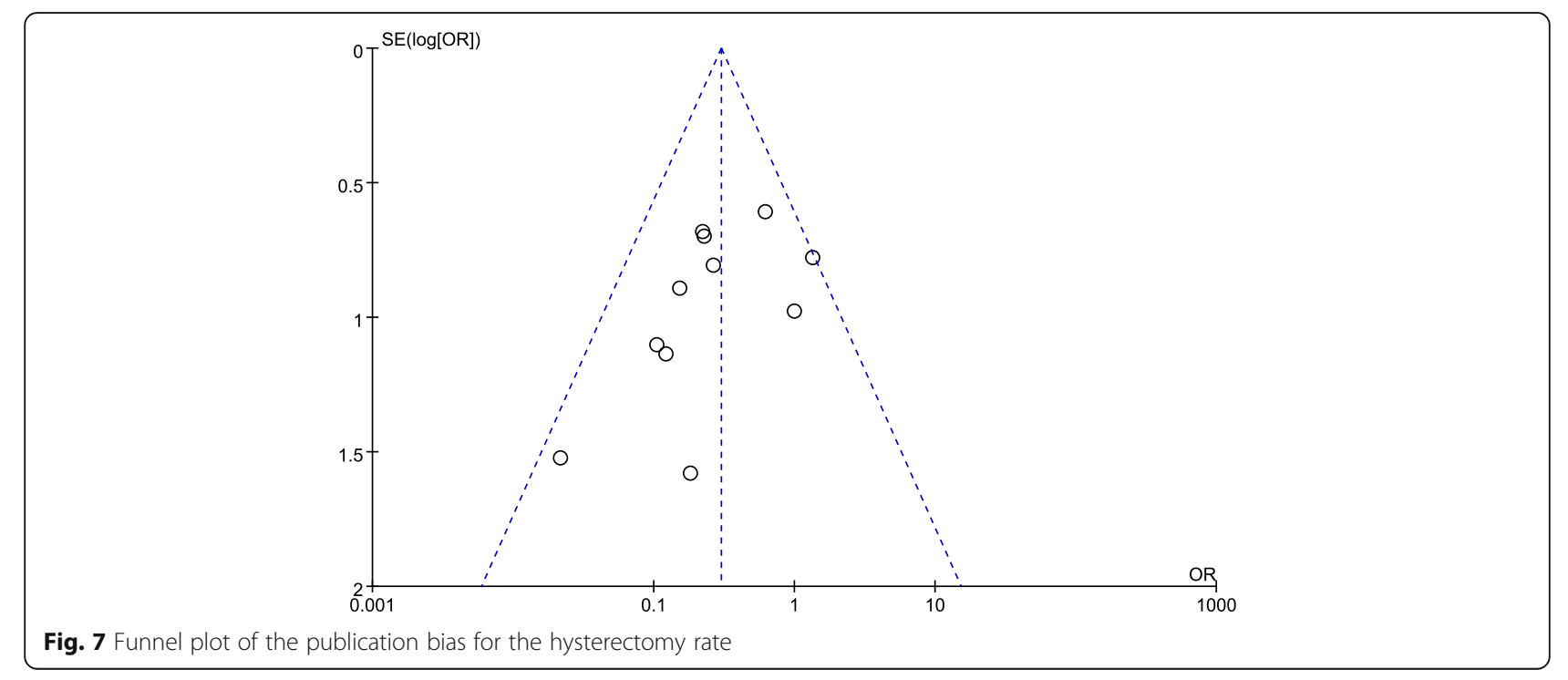


because of the extensive collateral circulation between the arteries in the pelvis [26], the hemostatic effect of iliac artery balloon occlusion, embolization or ligation is limited. Ramoni et al. [27] reported 4 cases of placenta accreta accompanied by postpartum hemorrhage after bilateral uterine artery ligation due to collateral circulation. Shrivastava et al. [28] reported no significant reduction in the blood loss or transfusion volume in patients with placenta accreta when bilateral internal iliac artery balloon occlusion was applied.

For AABO, the balloon is placed below the renal arteries to block most of the blood supply to the pelvic cavity, thereby exerting a better hemostatic effect. Yang et al. [23] and Wang et al. [25] reported significant reductions in the blood loss volume and the number of blood transfusions with $\mathrm{AABO}$ versus bilateral internal iliac artery occlusion. A systematic review compared the efficacy of balloon occlusion of the internal iliac arteries, abdominal aorta, uterine artery, and common iliac arteries and showed that AABO resulted in less blood loss and a lower rate of hysterectomy than the other methods [29].

No uniform standard for the total duration of balloon occlusion is available. Masamoto et al. [9] reported a case of a patient with placenta percreta treated with 80 min of continuous occlusion during cesarean section, with no obvious intraoperative or postoperative complications. In our study, 5 articles reported the occlusion time. The mean time ranged from $18 \mathrm{~min}$ to $36.95 \mathrm{~min}$ in these articles, with a maximum occlusion time of 80 min. However, occlusion was not continuous, allowing intermittent recovery of the blood supply. No limb necrosis, ischemia-reperfusion injury, functional renal impairment, or spinal cord or peripheral nerve injury was observed postoperatively during the follow-up period.

\section{Conclusion}

Placenta accreta caused severe obstetric hemorrhage and results in significant maternal morbidity and mortality. Abdominal aortic balloon occlusion (AABO), as a new technology, is becoming an important treatment for patients with placenta accrete. It has a beneficial effect by decreasing hemorrhaging and blood transfusion requirements during or after surgery and reduces the hysterectomy and DIC rates. It is safe and effective and should be promoted in patients with placenta accreta.

\section{Acknowledgements}

We would like to recognize support from the "111 program" of the Ministry of Education P.R.C and the State Administration of Foreign Experts Affairs P.R.C.

\section{Funding}

This work was financially supported by the National Key Research and Development Program of Reproductive Health \& Major Birth Defects Control and Prevention (No.2016YFC1000407), the National Natural Science Foundation of China (81601304), Key Program of International Cooperation of NSFC (81520108013), and the PhD Programs Foundation of the Ministry of Education of China (2013550311003).

\section{Availability of data and materials}

All data generated or analysed during this study are included in this published article.

\section{Authors' contributions}

Correspondence should be addressed to NS, 31426193@qq.com, and HQ qihongbocy@gmail.com. NS and HQ designed the study and collected all data. LC was responsible for writing introduction, results and discussion. XW was responsible for writing materials and methods. HW and QL performed data analysis. All authors read and approved the final manuscript.

\section{Ethics approval and consent to participate}

Not applicable

Consent for publication

Not applicable

\section{Competing interests}

The authors declare that they have no competing interests.

\section{Publisher's Note}

Springer Nature remains neutral with regard to jurisdictional claims in published maps and institutional affiliations.

\section{Author details}

${ }^{1}$ The Department of Obstetrics, The First Affiliated Hospital of Chongqing Medical University, Chongqing 400016, China. ${ }^{2}$ State Key Laboratory of Maternal and Fetal Medicine of Chongqing Municipality, Chongqing Medical University, Chongqing 400016, China. ${ }^{3}$ International Collaborative Laboratory of Reproduction and Development of Chinese Ministry of Education, Chongqing Medical University, Chongqing 400016, China.

Received: 12 October 2018 Accepted: 3 January 2019

Published online: 15 January 2019

\section{References}

1. Cook JR, Jarvis S, Knight M, Dhanjal MK. Multiple repeat caesarean section in the UK: incidence and consequences to mother and child. A national, prospective, cohort study. BJOG. 2013;120:85-91.

2. Fitzpatrick KE, Sellers S, Spark P, Kurinczuk JJ, Brocklehurst P, Knight M Incidence and risk factors for placenta accreta/increta/percreta in the UK: a national case-control study. PLoS One. 2012;7:e52893.

3. Committee ACOG. Opinion. Placenta accreta. Number 266, January 2002. American college of obstetricians and gynecologists. Int J Gynaecol Obstet. 2002;77:77-8

4. Rotas MA, Haberman S, Levgur M. Cesarean scar ectopic pregnancies: etiology, diagnosis, and management. Obstet Gynecol. 2006;107:1373-81.

5. Kassem GA, Alzahrani AK. Maternal and neonatal outcomes of placenta previa and placenta accreta: three years of experience with a twoconsultant approach. Int J Women's Health. 2013:5:803-10.

6. Shih JC, Liu KL, Shyu MK. Temporary balloon occlusion of the common iliac artery: new approach to bleeding control during cesarean hysterectomy for placenta percreta. Am J Obstet Gynecol. 2005;193:1756-8.

7. Tan YL, Suharjono H, Lau NL, Voon HY. Prophylactic bilateral internal iliac artery balloon occlusion in the management of placenta accreta: a 36month review. Med J Malaysia. 2016;71:111-6.

8. Horng HC, Hu WM, Tseng HS, Chang WH, Chao KC, Yang MJ. Uterine arterial embolization in the management of severe post-partum hemorrhage: a successful rescue method to avoid peripartum hysterectomy. J Chin Med Assoc. 2011;74:255-8

9. Masamoto H, Uehara H, Gibo M, Okubo E, Sakumoto K, Aoki Y. Elective use of aortic balloon occlusion in cesarean hysterectomy for placenta previa percreta. Gynecol Obstet Investig. 2009;67:92-5.

10. Sovik E, Stokkeland P, Storm BS, Asheim P, Bolas O. The use of aortic occlusion balloon catheter without fluoroscopy for life-threatening postpartum haemorrhage. Acta Anaesthesiol Scand. 2012;56:388-93.

11. Chen M, Xie L. Clinical evaluation of balloon occlusion of the lower abdominal aorta in patients with placenta previa and previous cesarean section: a retrospective study on 43 cases. Int J Surg. 2016;34:6-9.

12. Cui SH, Zhi YX, Zhang K, Zhang LD, Shen LN, Gao YN. Application of temporary balloon occlusion of the abdominal aorta in the treatment of 
complete placenta previa complicated with placenta accreta. Zhonghua Fu Chan Ke Za Zhi. 2016;51:672-7.

13. Duan $X$, Wang $Y$, Han $X$. Pernicious placenta previa with accreta: comparison of cesarean section combined with intermittent aortic balloon occlusion versus cesarean section alone. J Clin Radiol. 2016;35:1746-50.

14. Gong Z, Cheng X, Chi Y, Wang Z, Liu Z. Clinical curative effect of balloon occlusion of distal abdominal aorta in cesarean section for patients with pernicious placenta previa and placenta accreta. Chin J Interv Imaging Ther. 2017;14:351-4

15. Panici PB, Anceschi M, Borgia ML, Bresadola L, Masselli G, Parasassi T, et al. Intraoperative aorta balloon occlusion: fertility preservation in patients with placenta previa accreta/increta. J Matern Fetal Neonatal Med. 2012;25:2512-6.

16. Qiu Z, Chen L, Wu J, Hu J. Prophylactic abdominal aorta arteries balloon occlusion in cesarean section for pernicious placenta previa and placenta increta in third trimester. Chin J Pract Gynecol Obstet. 2015;31:1029-33.

17. Sun W, Duan S, Xin G, Xiao J, Hong F, Hong H, et al. Safety and efficacy of preoperative abdominal aortic balloon occlusion in placenta increta and/or percreta. J Surg Res. 2018;222:75-84.

18. Wang YL, Su FM, Zhang HY, Wang F, Zhe RL, Shen XY. Aortic balloon occlusion for controlling intraoperative hemorrhage in patients with placenta previa increta/percreta. J Matern Fetal Neonatal Med. 2017;30: 2564-8.

19. Wu Q, Liu Z, Zhao X, Liu C, Wang Y, Chu Q, et al. Outcome of pregnancies after balloon occlusion of the infrarenal abdominal aorta during caesarean in 230 patients with placenta praevia accreta. Cardiovasc Intervent Radiol. 2016:39:1573-9.

20. Xie L, Wang Y, Luo FY, Man YC, Zhao XL. Prophylactic use of an infrarenal abdominal aorta balloon catheter in pregnancies complicated by placenta accreta. J Obstet Gynaecol. 2017;37:557-61.

21. Wei LC, Gong GY, Chen JH, Hou PY, Li QY, Zheng ZY, et al. Application of lower abdominal aorta balloon occlusion technique by ultrasound guiding during caesarean section in patients with pernicious placenta previa. Zhonghua Yi Xue Za Zhi. 2018;98:930-4.

22. The 2007 recommendations of the international commission on radiological protection. ICRP publication 103. Ann ICRP 2007: 37: 1-332.

23. Yang $X$, Chen Z, You Y. The comparative study in perioperative temporary balloon occlusion of the distal abdominal aorta and perioperative temporary balloon occlusion of the internal iliac arteries in the therapy of patients with placenta accreta. J Pract Obstet Gynecol. 2016;32:684-8.

24. Song P, Wu N. The application of temporary balloon occlusion technique in performing cesarean section for patients with pernicious placenta previa. J Int Radiol. 2017;26:451-4.

25. Wang YL, Duan XH, Han XW, Wang L, Zhao XL, Chen ZM, et al. Comparison of temporary abdominal aortic occlusion with internal iliac artery occlusion for patients with placenta accreta - a non-randomised prospective study. Vasa. 2017:46:53-7.

26. Jaraquemada JMP, Mónaco RG, Barbosa NE, Ferle L, rriarte H, Conesa HA. Lower uterine blood supply: extrauterine anastomotic system and its application in surgical devascularization techniques. Acta Obstet Gynecol Scand. 2007:86:228-34.

27. Ramoni A, Strobl EM, Tiechl J, Ritter M, Marth C. Conservative management of abnormally invasive placenta: four case reports. Acta Obstet Gynecol Scand. 2013;92:468-71

28. Shrivastava V, Nageotte M, Major C, Haydon M, Wing D. Case-control comparison of cesarean hysterectomy with and without prophylactic placement of intravascular balloon catheters for placenta accreta. Am J Obstet Gynecol. 2007;197(402):e401-5.

29. Shahin Y, Pang CL. Endovascular interventional modalities for haemorrhage control in abnormal placental implantation deliveries: a systematic review and meta-analysis. Eur Radiol. 2018;28:2713-26.

Ready to submit your research? Choose BMC and benefit from:

- fast, convenient online submission

- thorough peer review by experienced researchers in your field

- rapid publication on acceptance

- support for research data, including large and complex data types

- gold Open Access which fosters wider collaboration and increased citations

- maximum visibility for your research: over $100 \mathrm{M}$ website views per year

At BMC, research is always in progress.

Learn more biomedcentral.com/submissions 